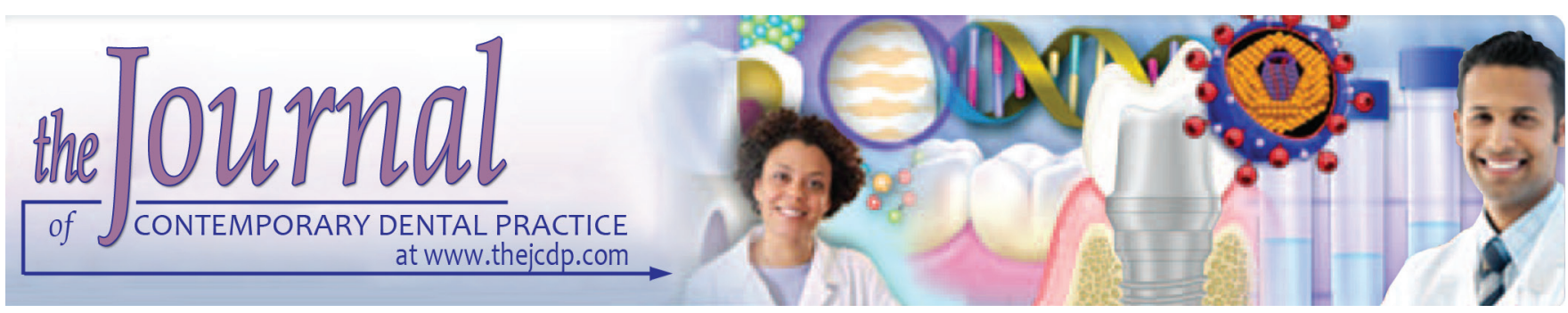

\title{
Study to evaluate the Efficacy of Resin-modified Glass Ionomer Cement Liner as a Direct Pulp Capping Material
}

\author{
${ }^{1}$ Abdul Shameem, ${ }^{2}$ Sabir Muliyar, ${ }^{3}$ Rekha P Thankachan, ${ }^{4}$ Jacob T Kalliath, ${ }^{5}$ Ummer Mangalath, ${ }^{6}$ Sadiya Mangalath
}

\begin{abstract}
Aim: The aim of the present in vivo study was to compare efficacy of light-cured resin-modified glass ionomer liner, Vitrebond $^{\mathrm{TM}}$ (3M ESPE) with Dycal ${ }^{\circledR}$ (Dentsply) on the healing of pulpal tissue in the event of a direct iatrogenic pulpal exposure.

Materials and methods: Experimental group consisted of $V$ itrebond ${ }^{\mathrm{TM}}$ (3M ESPE) resin-modified glass ionomer liner, and Vitremer $^{\mathrm{TM}}$ (3M ESPE) resin-modified glass ionomer cement $(\mathrm{GIC})$ in comparison with the control group of Dycal ${ }^{\circledR}$ (Dentsply) as liner and Poly $\mathrm{F}^{\circledR}$ (Dentsply) dental cement. Class $\mathrm{V}$ cavities were prepared in 32 sound premolars that were scheduled for orthodontic extraction, and the exposures were capped according to groups. Five teeth from each group were extracted under local anesthesia after an interval of 24 hours, 35 and 60 days, and evaluated for inflammation, fibrotic changes, formation of reparative dentin and bacterial examination.
\end{abstract}

Results: The present study did not show any statistically significant difference between two groups in terms of inflammation, fibrosis, reparative dentin formation, and bacterial examination.

Conclusion: This study shows that Vitrebond ${ }^{\mathrm{TM}}$ (3M ESPE) light-cured resin-modified glass ionomer liner can be used as an alternative to calcium hydroxide as a direct pulp capping material.

Clinical significance: Light-cured resin-modified glass ionomer liner can be an alternative for the calcium hydroxide-based liner for capping iatrogenic pulp exposures.

Keywords: Direct pulp capping, Dycal, Glass ionomer cement, latrogenic exposure, Reparative dentin.

How to cite this article: Shameem A, Muliyar S, Thankachan RP, Kalliath JT, Mangalath U, Mangalath S. Study to evaluate

1-4,6 Department of Conservative Dentistry and Endodontics MES Dental College and Hospital, Malappuram, Kerala, India

${ }^{5}$ Department of Oral Surgery, MES Dental College and Hospital Malappuram, Kerala, India

Corresponding Author: Abdul Shameem, Department of Conservative Dentistry and Endodontics, MES Dental College and Hospital, Malappuram, Kerala, India, e-mail: drabdulshameem@gmail.com the Efficacy of Resin-modified Glass lonomer Cement Liner as a Direct Pulp Capping Material. J Contemp Dent Pract 2018;19(9):1065-1071.

Source of support: Nil

Conflict of interest: None

\section{INTRODUCTION}

Human dental pulp has evoked much interest, as a specialized connective tissue located in an unyielding chamber of hard tissues around, with its particular arteriovenous supply and its dynamic cellular organization. Dental pulp maintains a unique environment, almost entirely encased in an unyielding chamber, often referred to as its own "coffin." In addition to this, the coronal pulp tissue lacks collateral blood supply, thereby extra nutrients and defense cells are not capable of reaching this coronal tissue as is seen in other healing tissues. Due to these reasons, the very attempt to save the pulp was viewed with suspicion and many believed that it was a fruitless effort. But now the emphasis has shifted to recovery of pulp following injury. Myriad of investigations and research has been conducted on dental pulp response and reaction to various restorative materials and procedures. Also, the ability of dental pulp to heal once exposed has been researched extensively.

Vital pulp exposure does occur in dental practice as well as in traumatic injuries. Once the exposure occurs, the clinician must make an immediate decision whether to cap the pulp or proceed with pulp removal. In case of pulp capping, there has been confusion over material to be used for the same, as in the past several years, new techniques have been promoted and older concept criticized. ${ }^{1}$ Iatrogenic pulpal exposures capped by dental students have been found to have a success rate of $92 \%$, wherein carious pulp exposures capped by dental students were found to be only $33 \% .^{2}$ It has been observed that pulp plays a crucial role in keeping dentin moist, 
supple (less brittle), and resilient, which serves to protect the teeth from forces of mastication ${ }^{3}$ and the success of direct pulp capping is largely dependent on the clinical situation under which it is performed and age, type, site, and size of pulpal exposure. ${ }^{4}$

History records Phillip Pfaff performing the first pulp capping procedure using small gold pieces over exposed pulp in 1,756 to promote healing. However, calcium hydroxide which was introduced into dentistry by Hermann forms the gold standard in treating direct and indirect pulpal exposures irrespective of its poor physical and mechanical properties. ${ }^{5}$ It has been observed that the highly alkaline $\mathrm{pH}$ of the calcium hydroxide causes superficial necrosis and subsequent formation of fiber-rich scar tissue. As a response to this, undifferentiated mesenchymal cells differentiate into secondary odontoblasts which stimulate the production of secondary or reparative dentin, resulting in "dentin bridge formation." Recent studies have shown this dentin bridge to have porosity and tunnel defects, leading to disintegration, paving way for microleakage. ${ }^{6}$ This may result in infection, inflammation and, finally, death of the pulp. Presence of bacteria within the restoration gap and adjacent dentin has been considered the major factor leading to pulp inflammation and eventual necrosis. ${ }^{7,8}$ Therefore, materials that have the advantages of calcium hydroxide and also overcome the disadvantages of the same were explored by different investigators, to varying degrees of success.

Glass ionomer cement, known for its chemical bonding and linear coefficient of thermal expansion similar to that of the tooth, has undergone a myriad of changes, since its introduction by Wilson and Kent in 1972. ${ }^{9}$ Although literature shows conflicting views of pulpal response toward glass ionomer when used in deep cavities as liners, recent studies on Vitrebond (resin-modified glass ionomer) have shown it to have an acceptable biocompatibility when used in clinical cases having remaining dentin thickness ranging from 342.3 to $436.1 \mu \mathrm{m} .{ }^{10}$ Therefore, the present study was undertaken to compare the efficacy of light-cured resin-modified glass ionomer liner, Vitrebond ${ }^{\mathrm{TM}}$ (3M ESPE) with Dycal ${ }^{\circledR}$ (Dentsply) on the healing of pulpal tissue in the event of a direct iatrogenic pulpal exposure.

\section{MATERIALS AND METHODS}

The present study was conducted in the Department of Conservative Dentistry and Endodontics, MES Dental College and Hospital, Perinthalmanna, Kerala, India. The study was approved by the Institutional Ethical Committee. Prior to study, treatment protocol and possible complications were explained to the patients and written informed consent was obtained.

Thirty-two vital human premolar teeth free of caries or any other defects in eight patients scheduled for orthodontic extraction were included in this study. Two teeth were excluded from the study due to a processing error. Age of the patients varied from 18 to 25 years. Teeth were radiographically examined to rule out any periapical pathology, periodontal defects, and resorptions.

The sample was divided into 15 teeth each in experimental and control groups. The experimental group samples were treated with Vitrebond ${ }^{\mathrm{TM}}$ (3M ESPE) lightcured glass ionomer liner and Vitremer ${ }^{\mathrm{TM}}$ (3M ESPE) glass ionomer restorative cement. The control group was treated with Dycal ${ }^{\circledR}$ (Dentsply) calcium hydroxide liner and Poly $\mathrm{F}^{\circledR}$ (Dentsply) cement. All the selected patients underwent thorough oral prophylaxis to remove any calculus or debris that would interfere with the treatment procedure. The test was standardized according to the American National Standards Institute/American Dental Association document number 41 for in vivo usage test.

The teeth were polished using pumice paste with rubber cup in a slow-speed micromotor handpiece. Infiltration anesthesia was secured and rubber dam isolation obtained for the tooth to be prepared. Uniform-sized class $\mathrm{V}$ cavities, approximately $1 \mathrm{~mm}$ coronal to the free gingival margin, measuring $2.5 \mathrm{~mm}$ cervico-occlusally and $3 \mathrm{~mm}$ mesiodistally with an optimal depth of $0.5 \mathrm{~mm}$ of remaining dentin, were prepared under efficient water spray coolant (Fig. 1A). Following this, pulpal floor was deepened using a round tungsten carbide bur in slow speed with coolant until exposure (Fig. 1B) was confirmed by the presence of hemorrhage. Bleeding from the exposure site was controlled by sterile cotton pellet compression for 1 to 2 minutes.

In the experimental group, Vitrebond was mixed as per the manufacturer's instruction. It was placed over the exposure site and the floor of the cavity, and light cured for 40 seconds. Vitremer restorative cement was mixed according to the manufacturer's instruction and placed over the Vitrebond liner/base material up to the cavosurface margin and was light cured for 40 seconds. Similarly, in the control group, standardized cavities were prepared on the opposite quadrants using the same criteria. Similarly, Dycal was placed according to the manufacturer's instruction followed by Poly-F cement restoration up to the cavosurface margin (Fig. 2).

Five teeth from each group were extracted under local anesthesia at time intervals of 24 hours, 35 and 60 days. The apical third of teeth were removed at once after extraction by means of a diamond disk using Airotor high-speed handpiece with coolant. To facilitate fixation of the pulpal tissue, the teeth were placed in $10 \%$ formalin 

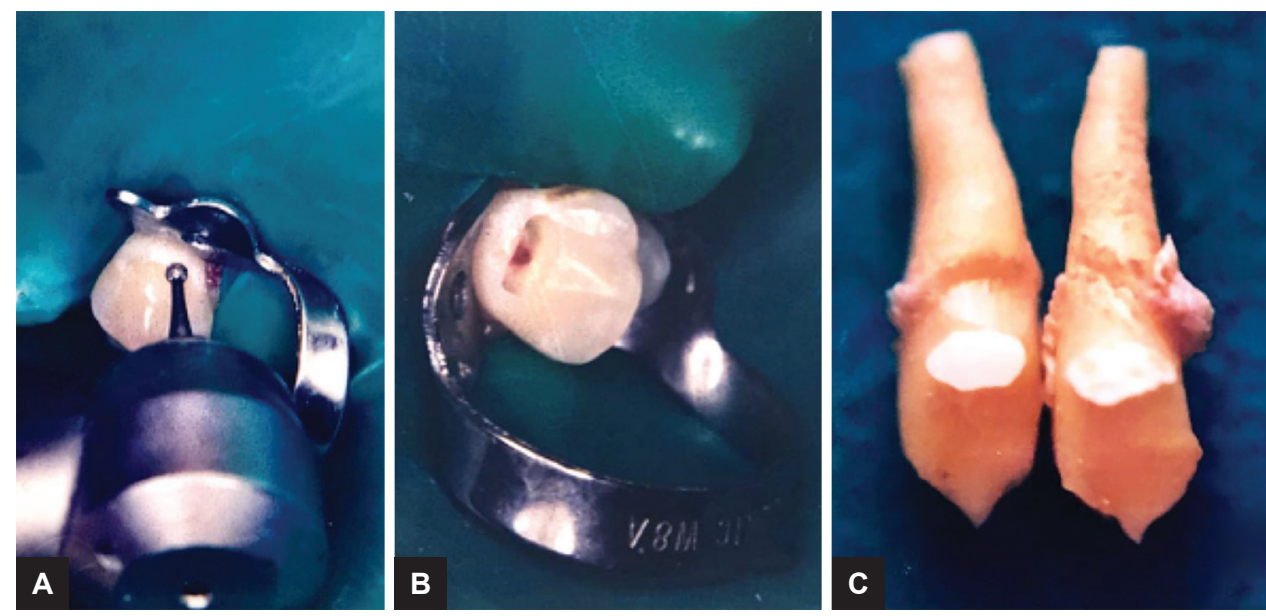

Figs 1A to C: (A) Class $V$ cavity preparation under rubber dam, (B) pulp exposure evident, (C) decalcification of teeth

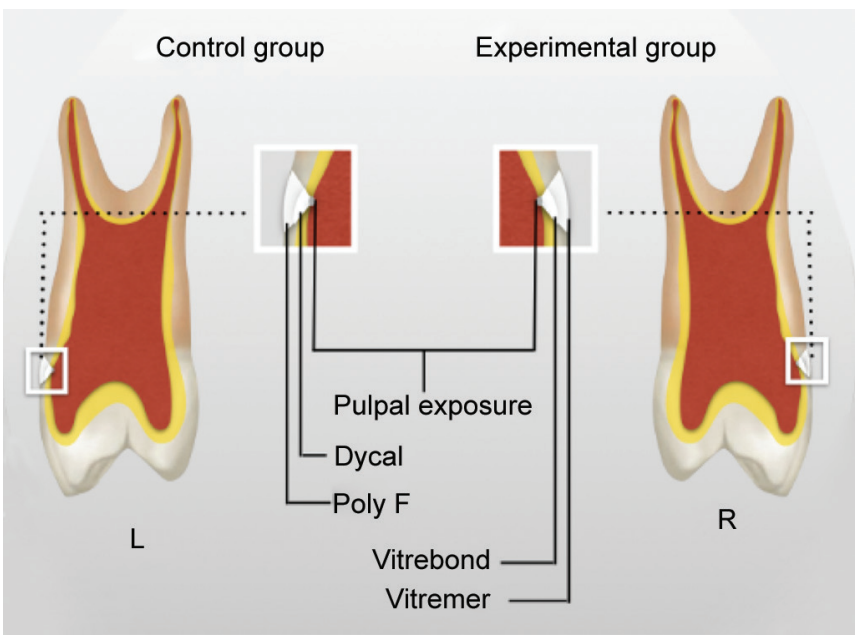

Fig. 2 Schematic representation of pulp capping

solution for 5 days. The teeth were then placed in 10\% formol nitric acid for decalcification (Fig. 1C). The solution was replaced every 6 hours, for 7 days. An ammonium oxalate precipitate test was used to confirm decalcification. Once the decalcification was complete, the teeth were embedded in a wax block and longitudinal section was made through the exposure site (Fig. 3A), of $4 \mu \mathrm{m}$ thickness using a soft tissue microtome (Fig. 3B). The sections were fixed on to the slide and stained by hematoxylin and eosin stains (Fig. 4). The specimens were evaluated for inflammation, fibrosis, and reparative dentin and graded accordingly (Tables 1 and 2). A separate evaluation criterion was made for evaluation at the end of 24 hours. Bacteriological examination for Gram-positive and Gram-negative organisms was carried out using modified Gram's stains ${ }^{10}$ (Brown and Brenn stain) (Table 3). The prepared stain was standardized using positive staining of Gram-positive and -negative samples.

\section{RESULTS}

All the patients were free of any clinical signs and symptoms of inflammation during the entire study period. The specimens were evaluated and graded for inflammation, fibrotic changes, formation of reparative dentin at 24 hours, 35 and 60 days and also bacterial examination as per criteria. The results of study are summarized in Table 4.

In the Dycal ${ }^{\circledR}$ (Dentsply) group, it was found that at 24 hours, one specimen showed uneven odontoblastic layer with subjacent slight inflammatory changes, three specimens showed moderate acute inflammatory changes, and one showed severe acute inflammatory change. None of the five specimens showed any bacterial
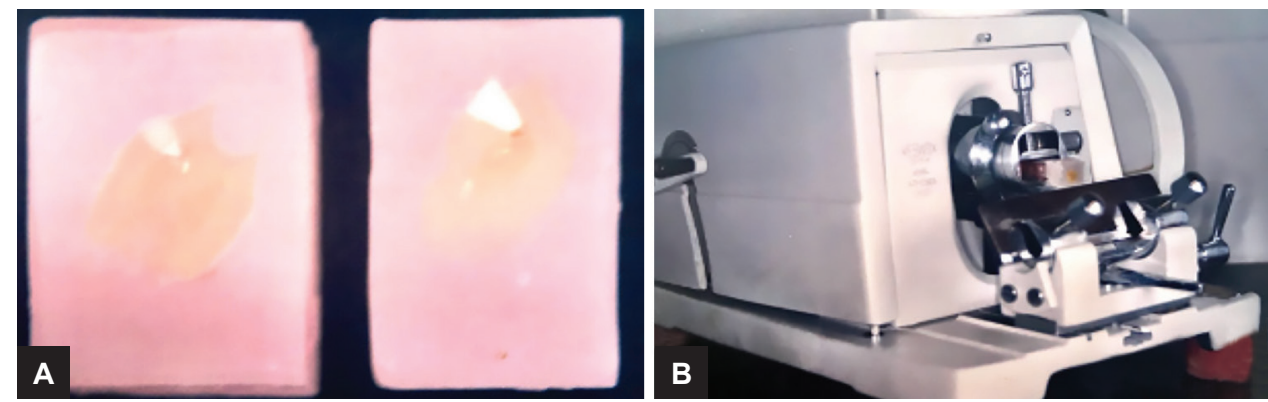

Figs 3A and B: (A) Decalcified sectioned teeth embedded in wax block, (B) soft tissue microtome used to section the specimen 

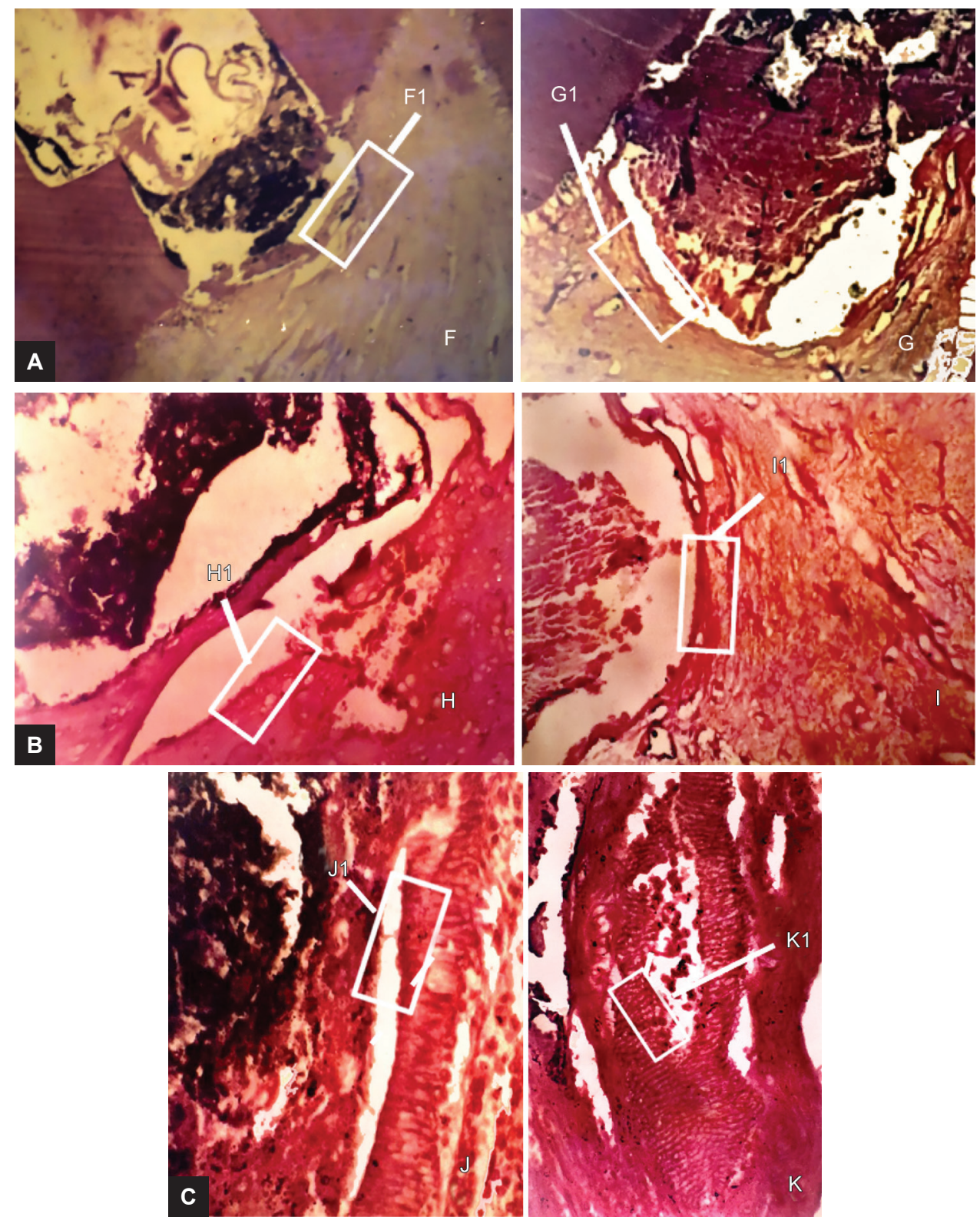

Figs 4A to C: (A) 24-hour evaluation (4× magnification): F-Dycal specimen; G-Vitrebond specimen; F1, G1—Dense infiltrate of PMNL cells. (B) 35-day evaluation (10x magnification): H—Dycal specimen; I-Vitrebond specimen; H1, I1—PMNL cell infiltrate. (C) 60-day evaluation (40× magnification): J-Dycal specimen; K-Vitrebond specimen; J1, K1 show reparative dentin formation at some distance from the capping material

Table 1: Inflammatory cell response

\begin{tabular}{lll}
\hline Grades & Inflammatory cell response (24 hours) & Inflammatory cell response (35 and 60 days) \\
\hline I & Normal or uneven odontoblastic layer below & None, either no inflammatory cells or scattered inflammatory cells \\
& tubules of remaining dentin with subjacent slight & present at the exposure site, beneath new hard tissue or adjacent to \\
inflammatory changes & the exposure site
\end{tabular}

contamination. At 35 days, two specimens showed scattered inflammatory cells adjacent to the exposure site, two specimens showed chronic inflammatory cells, and one specimen showed dense infiltrate of polymorphonuclear leukocytes (PMNL) cells. One specimen showed slight fibrosis, two showed mild response, whereas the rest two showed severe fibrosis. Reparative dentin was present directly adjacent to the capping in three, and in one 
Study to evaluate the Efficacy of Resin-modified GIC Liner

\begin{tabular}{|c|c|c|c|c|}
\hline \multirow{2}{*}{\multicolumn{3}{|c|}{$\begin{array}{l}\text { Table 2: Evaluation of fibrosis and reparative dentin formation } \\
\qquad \text { at } 35 \text { and } 60 \text { days }\end{array}$}} & \multicolumn{2}{|r|}{ Table 3: Examination of bacteria } \\
\hline & & & \multirow[b]{2}{*}{ Grades } & \multirow{2}{*}{$\begin{array}{l}\text { Bacteriological examination ( } 24 \text { hours, } 35 \text { and } \\
60 \text { days) }\end{array}$} \\
\hline \multirow[b]{3}{*}{ Grades } & \multirow{3}{*}{$\begin{array}{l}\text { Fibrosis ( } 35 \text { and } 60 \text { days) } \\
\text { (Increase in fibroblasts } \\
\text { and collagen fibers) }\end{array}$} & \multirow{3}{*}{$\begin{array}{l}\text { Reparative dentin } \\
\text { formation ( } 24 \text { hours, } \\
35 \text { and } 60 \text { days) }\end{array}$} & & \\
\hline & & & I & Absence of bacteria \\
\hline & & & \multirow{2}{*}{ ॥ } & \multirow{2}{*}{$\begin{array}{l}\text { Present along the cavity, including the axial wall } \\
\text { and axial floor, within the dentinal tubules and the } \\
\text { dental material }\end{array}$} \\
\hline 1 & None or light & $\begin{array}{l}\text { Directly adjacent to the } \\
\text { capping agent }\end{array}$ & & \\
\hline II & Mild & $\begin{array}{l}\text { At some distance from } \\
\text { the capping agent }\end{array}$ & III & $\begin{array}{l}\text { Present within the cut dentinal tubules of the } \\
\text { cavity preparation }\end{array}$ \\
\hline III & Severe & No evidence of the hard & IV & Present within necrotic pulp \\
\hline
\end{tabular}

Table 4: Observation results

\begin{tabular}{|c|c|c|c|c|c|c|c|c|c|c|c|c|c|c|c|}
\hline \multirow{2}{*}{$\frac{\text { Materials }}{\text { Dycal }}$} & \multirow[t]{2}{*}{ No. of teeth } & \multicolumn{4}{|c|}{ Inflammatory response } & \multicolumn{3}{|c|}{ Fibrosis } & \multicolumn{4}{|c|}{ Bacterial staining } & \multicolumn{3}{|c|}{ Reparative dentin } \\
\hline & & 1 & 2 & 3 & 4 & 1 & 2 & 3 & 1 & 2 & 3 & 4 & 1 & 2 & 3 \\
\hline & 24 hours & 1 & 3 & 1 & 0 & 0 & 0 & 0 & 5 & 0 & 0 & 0 & 0 & 0 & 0 \\
\hline & 35 days & 2 & 2 & 1 & 0 & 1 & 2 & 2 & 5 & 0 & 0 & 0 & 3 & 1 & 1 \\
\hline & 60 days & 2 & 2 & 1 & 0 & 1 & 2 & 2 & 5 & 0 & 0 & 0 & 5 & 0 & 0 \\
\hline \multirow[t]{3}{*}{ Vitrebond } & 24 hours & 0 & 2 & 3 & 0 & 0 & 0 & 0 & 5 & 0 & 0 & 0 & 0 & 0 & 0 \\
\hline & 35 days & 2 & 3 & 0 & 0 & 0 & 3 & 2 & 5 & 0 & 0 & 0 & 3 & 2 & 0 \\
\hline & 60 days & 3 & 0 & 2 & 0 & 2 & 2 & 1 & 5 & 0 & 0 & 0 & 0 & 5 & 0 \\
\hline
\end{tabular}

specimen, it was at some distance from the capping material. One specimen did not exhibit any reparative dentin formation. Bacterial staining was absent in any of the specimens. At the end of 60 days, two specimens showed no inflammatory cells at all. Two showed slight chronic inflammatory cells and one showed severe chronic inflammatory cells, which occurred as dense infiltrates. Two specimens showed severe fibrosis, two showed mild fibrosis, and one showed slight fibrosis. Coagulation necrosis was seen in all the specimens adjacent to the reparative dentin. Reparative dentin was seen adjacent to the capping material in all the five specimens. Bacterial infiltration was not present in any of the specimens.

In Vitrebond ${ }^{\mathrm{TM}}$ (3M ESPE) group, it was observed that at 24 hours, three specimens showed moderate acute chronic inflammatory changes and two showed severe acute inflammatory reactions. All the specimens were negative of any bacterial contamination. At 35 days, two specimens showed a scattered inflammatory reaction and three showed slight chronic inflammatory reactions. Three specimens showed mild fibrosis and two showed severe fibrosis. Reparative dentin was evident adjacent to the capping material in three specimens and at some distance from the capping agent in two specimens. None of the specimens showed bacterial contamination. At 60 days, three specimens showed no evidence of any inflammatory cells, whereas two showed evidence of severe inflammatory reaction. Two showed slight fibrosis, two showed mild fibrosis, and in one specimen, severe fibrosis was seen. Bacterial contamination was not seen in any specimen. All the five specimens were reparative at some distance to the capping material at the end of 60 days.
Statistical analysis was carried out using Fischer's chi-square test. Analysis showed no significant difference in the results of the two materials at the end of 24 hours, 35 and 60 days.

Over the decade, different materials have been tried out to maintain the vitality of the pulp. Survival of this specialized connective tissue using various materials in the event of an exposure has been debated upon by a number of investigators. The most advocated and timetested material for pulp capping was calcium hydroxide. The experimentation with other materials, such as mineral trioxide aggregate, tricalcium phosphate, dentin bonding agents, and cyanoacrylates gave varying degrees of success rates. Among these, resin-modified glass ionomers (RMGIs) have been reported to be cytotoxic to the pulp, ${ }^{11}$ while in one study, it was found to have a favorable response in the deep cavity as a liner. ${ }^{12}$ The present study evaluated the efficacy of RMGI, Vitrebond ${ }^{\mathrm{TM}}$ (3M ESPE) as direct pulp capping agent in iatrogenic pulpal exposure in comparison with Dycal ${ }^{\circledR}$ (Dentsply) as the standard.

According to Brannstrom, ${ }^{7}$ microleakage is thought to be the culprit for pulpal death rather than material toxicity itself. A direct correlation has been observed between the pulpal inflammation and the bacterial contamination. ${ }^{13}$ The antibacterial activity of calcium hydroxide has been attributed to release of hydroxyl ions, which causes damage to the bacterial cytoplasmic membrane, denaturation of proteins, or damage to the deoxyribonucleic acid. ${ }^{14}$ These antibacterial effects are short-lived, as it was found by Cox et $\mathrm{al}^{8}{ }^{8}$ that most of calcium hydroxide medicaments disintegrate and wash out over a period of six months, leading to a 'void' formation underneath the restoration. 
The concept of bonding, which revolutionized the field of restorative dentistry, plays an even greater role in minimizing or prevention of the microleakage. Sublining the exposure site with calcium hydroxide and then providing a base over this with GIC would, in fact, decrease the surface area for adhesion with the inherent risk of encouraging microleakage. ${ }^{15}$ The reparative dentin formed, by pulpal tissue in contact with calcium hydroxide have been found to have 'tunnel defects', this shortcoming along with solubility of calcium hydroxide leading to microleakage, will have adverse effect on the pulpal healing. ${ }^{16,17}$

In the present study, mild chronic inflammatory cells were seen localized just beneath the reparative dentin formation. Accumulation of macrophages was seen more in cases of Vitrebond ${ }^{\mathrm{TM}}$ than Dycal ${ }^{\circledR}$ but not statistically significant. This may be due to the rough surface texture of the material, and pulp interface that might encourage macrophage accumulation, which describes the tendency of macrophages to prefer rough surfaces. These chronic inflammatory cells may have acted as a stimulant for the differentiation of undifferentiated mesenchymal cells into odontoblasts, which in turn formed the reparative dentin. The infiltration of small lymphocytes and plasma cells in areas of chronic inflammation and wound healing concentrate proteins for use by other cells to aid in regeneration or replacement. ${ }^{18}$

Necrosis was not evident in any of the examined specimens at 24 hours, 35 and 60 days, which clearly indicates an absence of any material cytotoxicity for both groups. At 24-hour interval and 35 days, both groups showed a similar inflammatory reaction. On examination after 60 days, Vitrebond ${ }^{\mathrm{TM}}$ specimen exhibited complete resolution of inflammation, wherein Dycal ${ }^{\circledR}$ specimen showed slight inflammation; however, both the groups exhibited reparative dentin formation directly adjacent to the capping agent.

As rubber dam was used and caution was taken to provide a sterile environment, none of the specimens showed bacterial contamination during the allocated time period, which supports the literature of the role of bacteria in pulpal necrosis and eventual death of pulp tissue. From the literature, it is evident that pulpal healing in case of direct or indirect exposure is dependent upon a multitude of factors, but the role of inflammation has been underestimated in the healing of pulp. Necrosis or apoptosis, resulting from localized inflammation of pulp, has been considered to be destructive ${ }^{19}$ and the presence of inflammation cannot be just correlated to the presence of bacteria. Inflammation is body's repair function and not specifically related to the presence of microorganisms alone. As with any living tissue, when subjected to an insult either chemical or mechanical, pulp responds and reacts via inflammation. Whenever there occurs an irritation to or discontinuity in the odontoblastic lining, there occurs the accumulation of inflammatory cells as an immune response. Due to the limited collateral circulation of the pulpal tissue, it is a known fact that pulp takes time to resolve the inflammatory conditions. The inflammatory reaction has been considered as a precondition for the stimulation of progenitors associated in pulp repair. ${ }^{20}$

In the majority of studies related to pulpal healing or non-healing, healing following capping with medicaments direct or indirect extends to 60 days. This time frame seems to be short, for evaluation of pulp, especially when it is devoid of collateral circulation. The 90-day time frame will be a future directive to be considered to understand the pulpal healing process further. Since this study did not evaluate the 3-month time period, the persistence and effect of the inflammatory condition in long-term are not known.

\section{CONCLUSION}

The present study showed that resin-modified lightcured glass ionomer (Vitrebond ${ }^{\mathrm{TM}}$ ) can also be used as pulp capping agent in iatrogenic pulp exposures and the reparative dentin formed is comparable to that of reparative dentin formed with time-proven calcium hydroxide. The bacterial contamination via microleakage and not the material toxicity being the main cause for pulpal inflammation, any material that provides strong and permanent seal combined with antibacterial effect would suffice as an ideal pulp capping material. Though various other material has been proven favorable, none of the materials forms an adhesive bond with the tooth structure, thereby providing a permanent seal. Despite this, further stress is required on time period, the number of teeth and assessment of the quality of the reparative dentin formed in association with the two materials for the certainty of the outcome.

\section{REFERENCES}

1. Christensen GJ. Pulp capping 1998. J Am Dent Assoc 1998 Sep;129(9):1297-1299.

2. Al-Hiyasat AS, Barrieshi-Nusair KM, Al-Omari MA. The radiographic outcomes of direct pulp-capping procedures performed by dental students. J Am Dent Assoc 2006 Dec;137(12):1699-1705.

3. Stanley HR. Pulp capping: Conserving the dental pulp—can it be done? Is it worth it? Oral Surg Oral Med Oral Pathol 1989 Nov;68(5):628-639.

4. Qureshi A, Soujanya E, Nandakumar, Pratapkumar, Sambashivarao. Recent advances in pulp capping materials: an overview. J Clin Diagn Res 2014 Jan;8(1):316-321.

5. Jalan AL, Warhadpande MM, Dakshindas DM. A comparison of human dental pulp response to calcium hydroxide and Biodentine as direct pulp-capping agents. J Conserv Dent 2017 Mar-Apr;20(2):129-133.

6. Ghoddusi J, Forghani M, Parisay I. New approaches in vital pulp therapy in permanent teeth. Iran Endod J 2014 Winter;9(1):15-22. 
7. Brannstrom M. Communication between the oral cavity and the dental pulp associated with restorative treatment. Oper Dent 1984 Spring;9(2):57-68.

8. Cox CF, Bergenholtz G, Heys DR, Syed SA, Fitzgerald M, Heys RJ. Pulp capping of dental pulp mechanically exposed to oral microflora: a 1-2-year observation of wound healing in the monkey. J Oral Pathol 1985 Feb;14(2):156-168.

9. Wilson A, Kent B. A new translucent cement for dentistry. The glass ionomer cement. British Dental Journal. 1972;132(4):133-135.

10. Khoroushi M, Keshani F. A review of glass-ionomers: from conventional glass-ionomer to bioactive glass-ionomer. Dent Res J (Isfahan) 2013 Jul;10(4):411-420.

11. Modena KC, Casas-Apayco LC, Atta MT, Costa CA, Hebling J, Sipert CR, Navarro MF, Santos CF. Cytotoxicity and biocompatibility of direct and indirect pulp capping materials. J Appl Oral Sci 2009 Nov-Dec;17(6):544-554.

12. Hse KM, Leung SK, Wei SH. Resin-ionomer restorative materials for children: a review. Aust Dent J 1999 Mar;44(1):1-11.

13. Bergenholtz G, Cox CF, Loesche WJ, Syed SA. Bacterial leakage around dental restorations: its effect on the dental pulp. J Oral Pathol 1982 Dec;11(6):439-450.
14. Mohammadi Z, Shalavi S, Yazdizadeh M. Antimicrobial activity of calcium hydroxide in endodontics: a review. Chonnam Med J 2012 Dec;48(3):133-140.

15. Cox CF, Sübay RK, Ostro E, Suzuki S, Suzuki SH. Tunnel defects in dentin bridges: their formation following direct pulp capping. Oper Dent 1996 Jan-Feb;21(1):4-11.

16. Schuurs A, Gruythuysen R, Wesselink P. Pulp capping with adhesive resin-based compositevs.calcium hydroxide: a review. Dental Traumatology. 2000;16(6):240-250.

17. Witherspoon D. Vital Pulp Therapy with New Materials: New Directions and Treatment Perspectives-Permanent Teeth. Journal of Endodontics. 2008;34(7):S25-S28.

18. Seltzer, S.; Bender, I. The dental pulp. Philadelphia (PA): Lippincott; 1992.

19. Goldberg M, Njeh A, Uzunoglu E. Is pulp inflammation a prerequisite for pulp healing and regeneration? Mediators Inflamm 2015 Oct;2015:347649.

20. Zhai S, Wang Y, Jiang W, Jia Q, Li J, Wang W, Wang H, Ding Y, Wang P, Liu J, et al. Nemotic human dental pulp fibroblasts promote human dental pulp stem cells migration. Exp Cell Res 2013 Jun;319(10):1544-1552. 